Article

\title{
Efficient Synthesis of Purine Nucleoside Analogs by a New Trimeric Purine Nucleoside Phosphorylase from Aneurinibacillus migulanus AM007
}

\author{
Gaofei Liu ${ }^{1}$, Tiantong Cheng ${ }^{1}$, Jianlin $\mathrm{Chu}^{2, *}$, Sui $\mathrm{Li}^{2}$ and Bingfang $\mathrm{He}^{2, *}$ \\ 1 College of Biotechnology and Pharmaceutical Engineering, Nanjing Tech University, Nanjing 211800, China; \\ 201762100110@njtech.edu.cn (G.L.); Cttdk123@163.com (T.C.) \\ 2 School of Pharmaceutical Sciences, Nanjing Tech University, Nanjing 211800, China; \\ 1303160204@njtech.edu.cn \\ * $\quad$ Correspondence: cjl2fl@126.com (J.C.); bingfanghe@njtech.edu.cn (B.H.); Tel.: +86-025-58139396 (J.C. \& B.H.)
}

Received: 15 November 2019; Accepted: 24 December 2019; Published: 26 December 2019

\begin{abstract}
Purine nucleoside phosphorylases (PNPs) are promising biocatalysts for the synthesis of purine nucleoside analogs. Although a number of PNPs have been reported, the development of highly efficient enzymes for industrial applications is still in high demand. Herein, a new trimeric purine nucleoside phosphorylase (AmPNP) from Aneurinibacillus migulanus AM007 was cloned and heterologously expressed in Escherichia coli BL21(DE3). The AmPNP showed good thermostability and a broad range of $\mathrm{pH}$ stability. The enzyme was thermostable below $55^{\circ} \mathrm{C}$ for $12 \mathrm{~h}$ (retaining nearly $100 \%$ of its initial activity), and retained nearly $100 \%$ of the initial activity in alkaline buffer systems ( $\mathrm{pH} 7.0-9.0$ ) at $60^{\circ} \mathrm{C}$ for $2 \mathrm{~h}$. Then, a one-pot, two-enzyme mode of transglycosylation reaction was successfully constructed by combining pyrimidine nucleoside phosphorylase (BbPyNP) derived from Brevibacillus borstelensis LK01 and AmPNP for the production of purine nucleoside analogs. Conversions of 2,6-diaminopurine ribonucleoside (1), 2-amino-6-chloropurine ribonucleoside (2), and 6-thioguanine ribonucleoside (3) synthesized still reached $>90 \%$ on the higher concentrations of substrates (pentofuranosyl donor: purine base; 20:10 mM) with a low enzyme ratio of BbPyNP: AmPNP $(2: 20 \mu \mathrm{g} / \mathrm{mL})$. Thus, the new trimeric AmPNP is a promising biocatalyst for industrial production of purine nucleoside analogs.
\end{abstract}

Keywords: trimeric nucleoside phosphorylase; thermostability; purine nucleoside analogs; enzyme ratio

\section{Introduction}

Up to now, nucleoside analogs have been significant sources of antiviral and anticancer drugs [1-3], among which purine nucleoside analogs are widely used for the treatment of leukemia $[4,5]$ and are also important precursors of several drugs [6,7]. To date, most purine nucleoside analogs are mainly synthesized by chemical methods [8-10]. However, biotechnological or enzymatic synthesis of purine nucleosides has become an attractive alternate to chemical synthesis, due to its higher chemo-, regio-, and stereoselectivity and greener reaction conditions [11]. Moreover, enzymatic synthesis of nucleosides circumvented multiple steps of activation, protection, and deprotection of functional groups [12,13], demonstrating great potential for the industrial production.

Nucleoside phosphorylases (NPs) catalyze the reversible cleavage of the glycosidic bond of (deoxy)ribonucleosides in the presence of inorganic orthophosphate $(\mathrm{Pi})$ to generate a nucleobase and $\alpha$-D-(deoxy) ribose-1-phosphate [14]. NPs include pyrimidine NPs (PyNPs, EC 2.4.2.2) and purine NPs (PNPs, EC 2.4.2.1). PyNPs show substrate specificity for the phosphorolysis of pyrimidine 
nucleosides, while PNPs are specific for purine nucleoside substrates [15]. For the effective formation of purine nucleosides, PyNPs and PNPs are usually combined in a one-pot, two-enzyme reaction system. For example, PNP from T. thermophilus and PyNP from Geobacillus thermoglucosidasius were used as biocatalysts to synthesize 2,6-diaminopurine ribonucleoside, which obtained a yield of $95.3 \%$ using uridine and 2,6-diaminopurine (2:1 mM) as substrates [16].

PNPs play a more important role in this system, which determines the yield of purine nucleosides. Currently, most PNPs are divided into trimeric PNPs and hexametric PNPs based on molecular mass, protein structure, or substrate specificity. Trimeric PNPs are isolated mainly from mammalian cells, including human erythrocytes [17] and bovine brain cells [18], which have a subunit molecular mass of approximately $31 \mathrm{kDa}$ and display specific activity toward guanosine and inosine. The hexametric PNPs are mostly isolated from bacterial species like Salmonella typhimurium [19] and Aeromonas hydrophila [20], which exhibit a phosphorolysis activity against adenosine and some derivatives, and have a subunit molecular mass of approximately $26 \mathrm{kDa}$. Although trimeric PNPs have good thermal stability, they have narrower substrate specificity. Therefore, only a few trimeric PNPs have been reported for purine nucleoside synthesis, which limits its application in industrial production. Therefore, it is still very urgent to screen and discover new trimeric PNPs.

The high price of enzymes increases the production cost in the enzyme-catalyzed synthesis industry. An appropriate enzyme ratio can not only increase the yield of the product, but also reduce the use of one enzyme, thus reducing the production cost. Zhou et al. used GtPNP and TtPyNP (enzyme ratio; 2:1) to synthesize purine nucleoside analogs with high yield [16]. Subsequently, their lab also reported that purine nucleosides with a higher yield were also synthesized by the combination of TtPyNP and GtPNP (enzyme ratio; 1:1) [21]. Therefore, in order to reduce the production cost, the optimization of the enzyme ratio is also necessary.

In this study, a trimeric PNP was cloned from Aneurinibacillus migulanus AM007 (CCTCC NO. M2016404) and heterologously expressed in Escherichia coli BL21(DE3). This enzyme named AmPNP was characterized. Interestingly, it is different from trimeric PNPs in the phosphorolysis activity of adenosine. Highly efficient synthesis of purine nucleosides analogs was successfully achieved in the one-pot, two-enzyme transglycosylation reaction catalyzed by AmPNP and PyNP derived from Brevibacillus borstelensis LK01 (BbPyNP) [22]. In particular, the ratio of BbPyNP and $A m P N P$ was optimized for the one-pot, two-enzyme reaction, greatly reducing the production cost.

\section{Results and Discussion}

\subsection{Sequence Analysis, Cloning, Expression, and Purification of AmPNP}

In this study, in order to screen the trimeric PNP with thermostability, BsPNP (GenBank: WP_015714207) from B. subtilis was selected as a template to mine thermostable PNPs among the genomes of 24 thermostable strains in our lab [23]. After preliminary experiments, the PNP from A. migulanus AM007, with higher enzyme activity toward purine nucleosides, was selected as a potential biocatalyst for the synthesis of purine nucleoside analogs. The strain A. migulanus AM007 was deposited at the CCTCC (accession number of CCTCC NO. M2016404).

The open-reading frame (ORF) of the AmPNP gene (813 bp) corresponded to 270 amino acid residues. The amino acid sequence of $A m P N P$ from $A$. migulanus AM007 was analyzed with sequence alignment (Supplementary Material, Table S1), which had a high identity of $66.1 \%$ with trimeric BsPNP from B. subtilis. The amino acid sequence of $A m P N P$ showed 46.4\%, 45.3\%, 14.7\%, and 13.1\% identity with the sequences of PNPs from humans, bovine, E. coli, and Aeromonas hydrophila, respectively, showing that it is more similar to trimeric PNPs.

A phylogenetic tree was created based on the sequences of $A m P N P$ and other reported trimeric and hexametric PNPs (Figure 1). The phylogenetic tree indicates that the trimeric PNPs from the bacterial species were a special subfamily of PNPs that displayed a different branch from the trimeric 
PNPs derived from animals. This implies that trimeric PNPs from bacterial species are different from traditional trimeric PNPs from animals in structure and function.
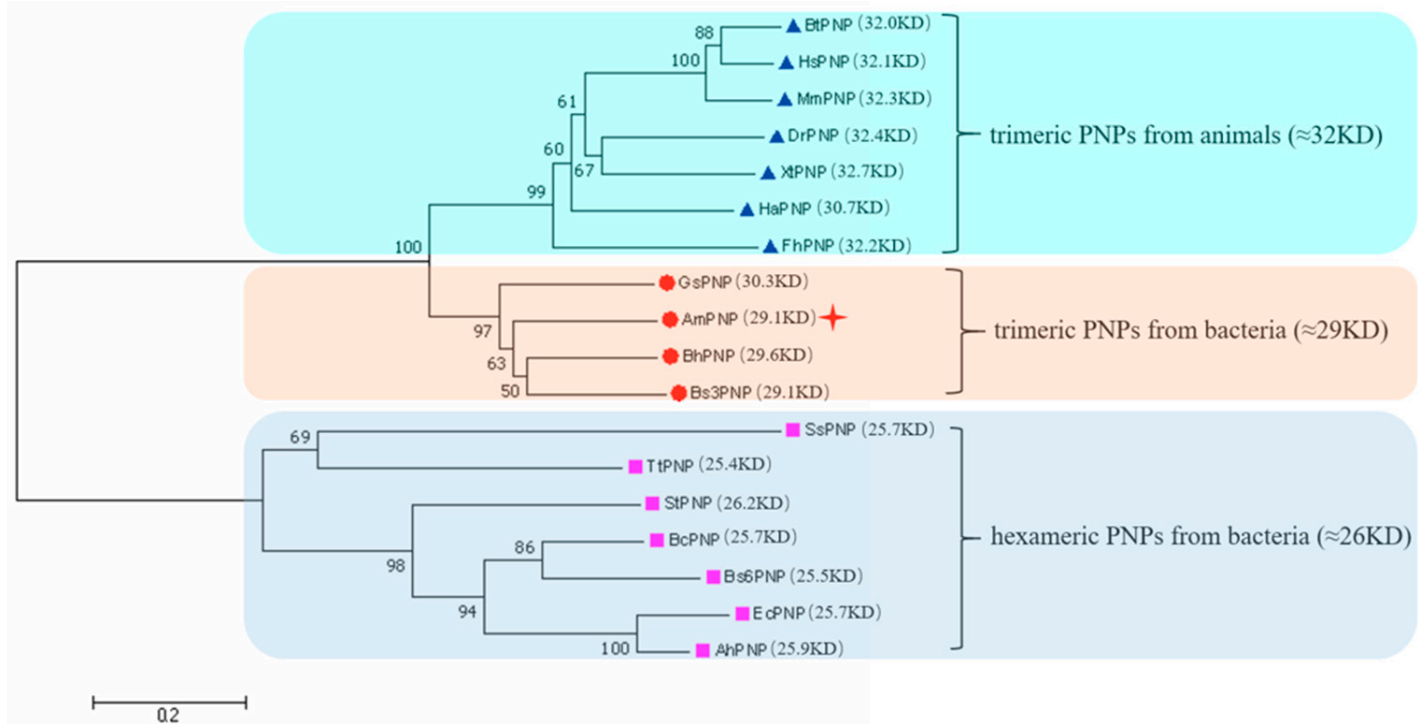

Figure 1. Phylogenetic analysis of purine nucleoside phosphorylases (PNPs). AhPNP (GenBank:WP_049045821) from Aeromonas hydrophila; BcPNP (GenBank:WP_098273438) from Bacillus cereus; BhPNP (GenBank: WP_010897696) from Bacillus halodurans; BtPNP (GenBank: AAX46392) from Bos taurus; Bs3PNP (GenBank: WP_015714207) from Bacillus subtilis; Bs6PNP (GenBank: WP_044428467) from Bacillus subtilis; DrPNP (GenBank: NP_998476) from Danio rerio; EcPNP (GenBank: AAN83888) from Escherichia coli; FhPNP (GenBank: XP_012736771) from Fundulus heteroclitus; GsPNP (GenBank: WP_053414649) from Geobacillus stearothermophilus; HaPNP (GenBank:KFP95377) from Haliaeetus albicilla; HsPNP (GenBank: NP_000261) from Homo sapiens; MmPNP (GenBank: NP_038660) from Mus musculus; SsPNP (GenBank: WP_009988635) from Sulfolobus solfataricus; StPNP (GenBank: WP_011681178) from Streptococcus thermophilus; TtPNP (GenBank: WP_096412123) from Thermus thermophilus; and XtPNP (GenBank: NP_001006720) from Xenopus tropicalis.

The gene encoding AmPNP (GenBank accession number: MH992394) from A. migulanus AM007 was successfully expressed in E. coli BL21(DE3). SDS-PAGE analysis of the recombined AmPNP revealed a thick band of approximately $29 \mathrm{kDa}$ corresponding to the possible subunit molecular mass of the enzyme. The $6{ }^{*} \mathrm{His}$-tagged (N-terminal) recombinant $A m \mathrm{PNP}$ was purified with $\mathrm{Ni}^{2+}$-affinity chromatography from the cell extract, and purified AmPNP was obtained with high purity (Figure 2a). The molecular weight of the purified $A m P N P$ was about $87 \mathrm{kDa}$, as analyzed with size-exclusion chromatography (Figure 2b,c). According to the SDS-PAGE analysis and gel-filtration chromatography results, the $A m$ PNP obtained from $A$. migulanus AM007 was a trimeric protein complex, which was consistent with the observation reported in the phylogenetic tree. 


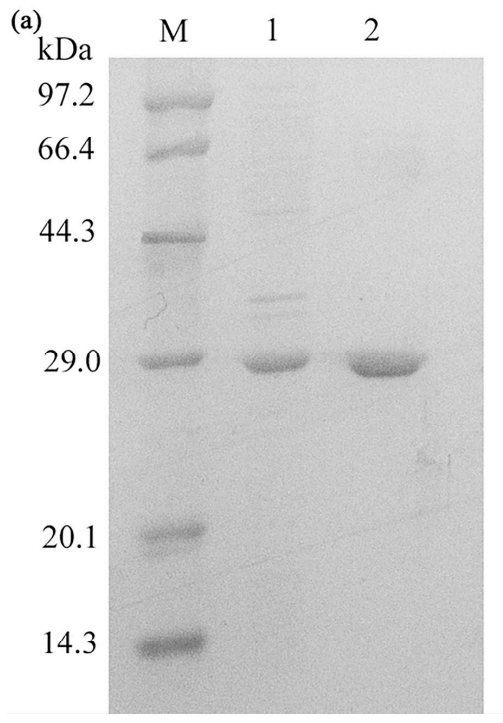

(b)

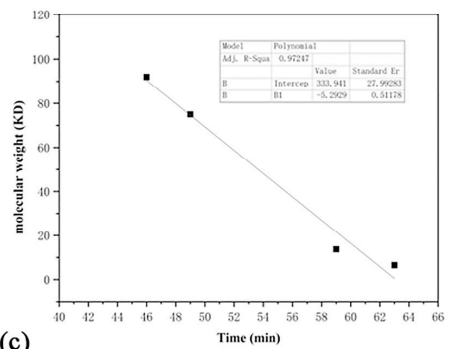

(c)

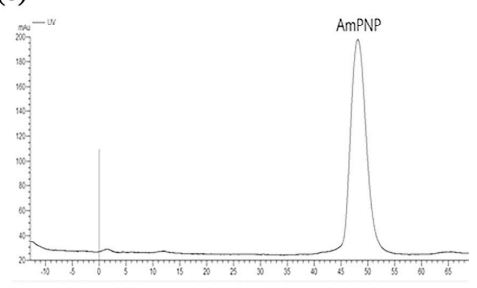

Figure 2. Molecular weight analysis of $A m P N P$. (a) Dodecyl sulfate-polyacrylamide gel electrophoresis (SDS-PAGE) analysis of purified AmPNP. Lane M: marker; Lane 1: crude enzymes; Lane 2: enzyme of $A m \mathrm{PNP}$ purified by $\mathrm{Ni}^{2+}$ column. (b) Analysis of $A m \mathrm{PNP}$ by gel filtration chromatography. The condition was conducted as following: an ÄKTA pure system and a column Superdex 200 Increase 10/300 GL were used. The standard proteins and the purified AmPNP sample were dissolved in the buffer ( $0.01 \mathrm{M}$ phosphate buffer, $0.14 \mathrm{M} \mathrm{NaCl}, \mathrm{pH} 8.0$ ) with the final concentration of $2 \mathrm{mg} / \mathrm{mL}$, respectively. For analysis, the flow rate was set at $0.3 \mathrm{~mL} / \mathrm{min}$ and the inject volume was $500 \mu \mathrm{L}$.

\subsection{Specific Activities of AmPNP Toward Various Purine Nucleosides}

A variety of purine nucleosides were used for the exploration of the substrate spectrum of $A m P N P$ (Table 1). The highest activity was obtained for inosine among purine nucleosides. According to previous literature [14], trimeric PNPs did not display specific activity toward adenosine. Interestingly, the trimeric AmPNP could cleave adenosine by phosphorolysis. This also suggested that the substrate specificity of the trimeric PNPs from bacterial species were different from trimeric PNPs from animals. In addition, the $\mathrm{K}_{\mathrm{cat}} / \mathrm{K}_{\mathrm{m}}$ values (Table 2) of $A m \mathrm{PNP}$ for inosine and guanosine were considerably higher than other PNPs, such as the PNP from Aeropyrum pernix K1 [24], indicating that it could serve as a useful biocatalyst in biochemistry and industrial biotechnology.

Table 1. Substrate specificity of $A m P N P$.

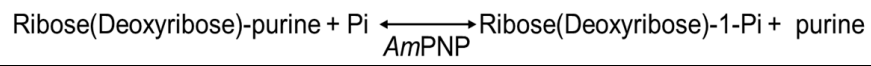

\begin{tabular}{ccc}
\hline Substrate & Phosphorolysis (\%) & Relative Activity (\%) \\
\hline Inosine & $32.7 \pm 3.9$ & $100 \pm 1.5$ \\
Guanosine & $21.9 \pm 4.9$ & $69.7 \pm 4.8$ \\
Adenosine & $9.5 \pm 2.1$ & $3.1 \pm 1.7$ \\
2' $^{\prime}$ Deoxyadenosine & 0 & 0 \\
2'-Deoxyguanosine $^{\prime}$-Deng & $16.2 \pm 1.3$ & $17.2 \pm 4.2$ \\
\hline
\end{tabular}

The phosphorolysis reactions catalyzed by the enzyme toward different purine nucleosides ( $10 \mathrm{mM})$ were conducted under $50{ }^{\circ} \mathrm{C}$ and $\mathrm{pH} 8.0\left(10 \mathrm{mM} \mathrm{Na}_{2} \mathrm{HPO}_{4} / \mathrm{KH}_{2} \mathrm{PO}_{4}\right)$ from $0 \mathrm{~h}$ to $48 \mathrm{~h}$. Samples were taken every $5 \mathrm{~min}$, and $50 \mu \mathrm{L}$ of the mixture was added to $950 \mu \mathrm{L}$ methanol for reaction termination. Data are represented as mean $\pm \mathrm{SD}(\mathrm{n}=3$ ). Equilibrium was reached in the applied reactions and phosphorolysis (\%) was absolute conversion (\%). Maximum enzyme activity of $A m P N P$ was $83 \mathrm{IU} / \mathrm{mg}$ for inosine and relative activity was set $100 \%$. 
Table 2. Kinetic parameters for $A m P N P$ with various purine nucleosides.

\begin{tabular}{cccc}
\hline Substrate & $\mathbf{K}_{\mathbf{m}}(\mathbf{m o l} / \mathbf{L})$ & $\mathbf{K}_{\text {cat }}\left(\mathbf{s}^{-\mathbf{1}}\right)$ & $\mathbf{K}_{\text {cat }} / \mathbf{K}_{\mathbf{m}}\left(\mathbf{s}^{-\mathbf{1}} \mathbf{M}^{-\mathbf{1}}\right)$ \\
\hline Inosine & $5.30 \times 10^{-3}$ & $6.38 \times 10^{4}$ & $1.21 \times 10^{7}$ \\
Guanosine & $1.16 \times 10^{-3}$ & $1.84 \times 10^{4}$ & $1.58 \times 10^{7}$ \\
Adenosine & $1.45 \times 10^{-3}$ & $1.43 \times 10^{1}$ & $9.92 \times 10^{3}$
\end{tabular}

In total, $1 \mathrm{~mL}$ of reaction mixture was composed of $10 \mathrm{mM}$ sodium phosphate buffer ( $\mathrm{pH}$ 8.0), an appropriate amount of $A m \mathrm{PNP}$, and $0.5-5 \mathrm{mM}$ substrates. The reaction mixture was incubated at $50^{\circ} \mathrm{C}$. Samples were taken every $5 \mathrm{~min}$, and $50 \mu \mathrm{L}$ of the mixture was added to $950 \mu \mathrm{L}$ methanol for reaction termination.

\subsection{Characterization of AmPNP}

The purified $A m \mathrm{PNP}$ was used to determine its biochemical properties. The AmPNP exhibited maximum phosphorolysis activity (Scheme 1 ) at a temperature of $70{ }^{\circ} \mathrm{C}$ (Figure 3a). The enzyme retained nearly $100 \%$ of its activity below $55^{\circ} \mathrm{C}$ for $12 \mathrm{~h}$ (Figure $3 \mathrm{~b}$ ), and the half-life period of AmPNP was $78.6 \mathrm{~h}, 37.3 \mathrm{~h}$, and $6.9 \mathrm{~h}$ at temperatures of $55^{\circ} \mathrm{C}, 60^{\circ} \mathrm{C}$, and $65^{\circ} \mathrm{C}$, respectively (Supplementary Material, Table S2). Overall, the AmPNP showed good thermostability, which was useful for industrial purine nucleosides synthesis done at a relatively high temperature to increase the solubility of substrate. The highest phosphorolysis activity of $A m \mathrm{PNP}$ was observed at a pH of 7.5 (Figure 3c). The enzyme retained nearly $100 \%$ of the initial activity in the alkaline buffer systems (pH 7.0-8.0) at $60{ }^{\circ} \mathrm{C}$ for $2 \mathrm{~h}$ (Figure 3d). The broad range of $\mathrm{pH}$ stability by $A m \mathrm{PNP}$ is facilitated to adjust the reaction $\mathrm{pH}$ with two-enzyme reaction. Therefore, the application of $A m P N P$ in industrial production has become more promising.

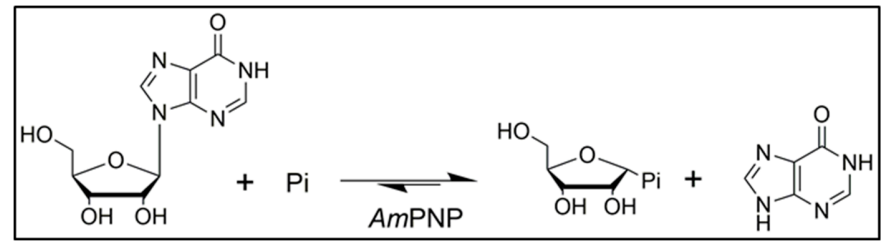

Scheme 1. Phosphorylation of inosine with AmPNP.

(a)

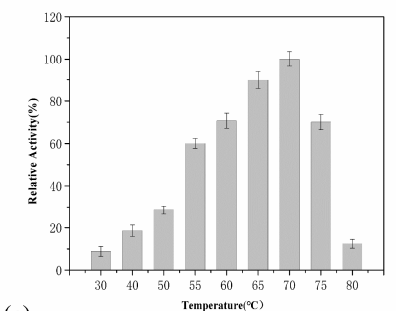

(c)

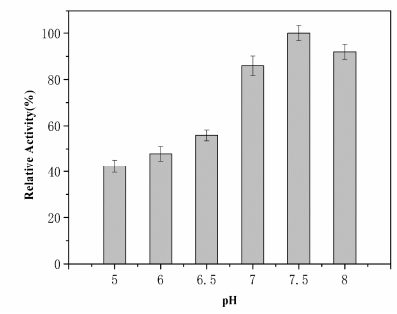

(b)

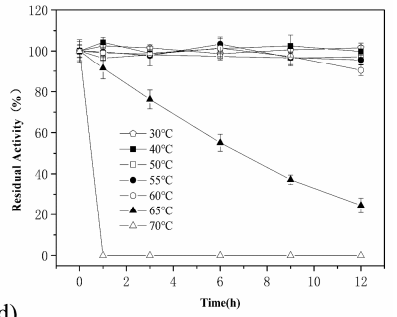

(d)

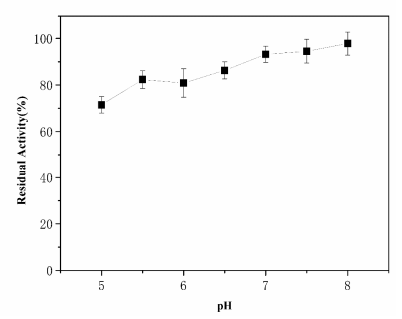

Figure 3. Effects of temperature and $\mathrm{pH}$ on the activity and stability of AmPNP. (a) Effect of temperature on the activity of $A m P N P$. The highest activity was set to $100 \%$. (b) Effects of temperature on stability of AmPNP. The initial activity was set to $100 \%$. (c) Effect of $\mathrm{pH}$ on the activity determined by assaying the activity at $60{ }^{\circ} \mathrm{C}$ in $10 \mathrm{mM} \mathrm{Na} 2 \mathrm{HPO}_{4} / \mathrm{KH}_{2} \mathrm{PO}_{4}$ buffer. The highest activity was set to $100 \%$. (d) Effect of $\mathrm{pH}$ on stability determined by assaying the residual activity of $A m \mathrm{PNP}$ after $2 \mathrm{~h}$ at $60{ }^{\circ} \mathrm{C}$ and different $\mathrm{pH}$ values in $10 \mathrm{mM} \mathrm{Na}_{2} \mathrm{HPO}_{4} / \mathrm{KH}_{2} \mathrm{PO}_{4}$ buffer. The highest activity was set to $100 \%$. The activity of AmPNP was determined in $10 \mathrm{mM} \mathrm{Na} 2 \mathrm{HPO}_{4} / \mathrm{KH}_{2} \mathrm{PO}_{4}$ buffer $(\mathrm{pH} 8.0)$ with $10 \mathrm{mM}$ inosine. 
2.4. Effect of Temperature and pH on Two-Enzyme Biosynthesis of 2-Amino-6-chloropurine Ribonucleoside (2)

In order to efficiently synthesize halogenated purine nucleoside, it was necessary to conduct the transglycosylation reaction of $A m P N P$ as the reported two-enzyme system [16]. We previously reported that BbPyNP from Brevibacillus borstelensis LK01 catalyzed the phosphorolysis of thymidine, 2 -deoxyuridine, uridine, and 5-methyuridine [22]. What is more, the $\mathrm{pH}$ and thermostability of $B b$ PyNP were nearly similar to those of AmPNP from A. migulanus AM007. Therefore, it is more favorable for synthesis of purine nucleoside by combining BbPyNP and AmPNP (Scheme 2).

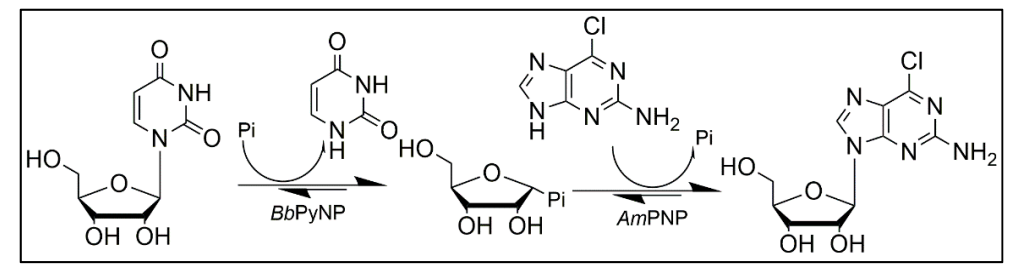

Scheme 2. Enzymatic synthesis of 2-amino-6-chloropurine ribonucleoside.

Using pyrimidine nucleosides as donors, several purine nucleosides, including 2-amino-6-chloropurine ribonucleoside (2), were synthesized with BbPyNP and AmPNP (ratio of 0.1:1) and the conditions of the one-pot, two-enzyme reaction were studied (Figure 4). The optimum temperature for the $A m \mathrm{PNP}$ and $\mathrm{BbPyNP}$ enzymes was approximately $55{ }^{\circ} \mathrm{C}$, and the yield of the 2-amino-6-chloropurine ribonucleoside (2) product reached approximately 81.2\% (Figure 3a). As shown in Figure 3b, a conversion $>70 \%$ was achieved from $\mathrm{pH} 6.0$ to 8.0 in the one-pot, two-enzyme reaction. The maximum 2-amino-6-chloropurine ribonucleoside (2) product formation reached approximately $92.8 \%$ at $\mathrm{pH} 7.0$ and $55{ }^{\circ} \mathrm{C}$ under relatively high substrate concentrations (ratio of uridine to purine of 20:10 mM) (Supplementary Material, Figure S1).

(a)

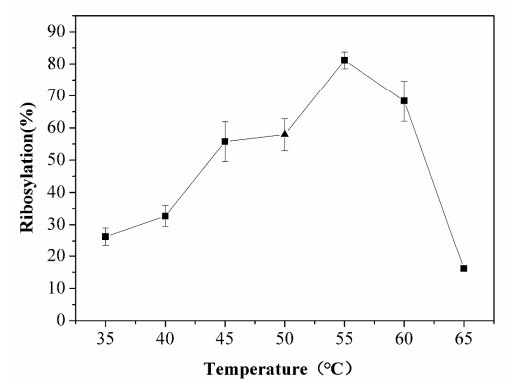

(b)

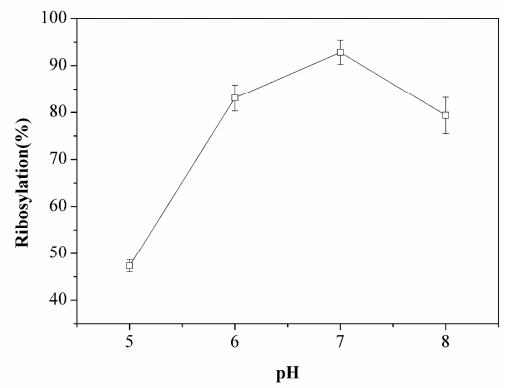

Figure 4. Effect of temperature and $\mathrm{pH}$ on biosynthesis of 2-amino-6-chloropurine ribonucleoside BbPyNP: AmPNP in a ratio of 2:20 $\mu \mathrm{g} / \mathrm{mL}$. The reaction mixture $(1.0 \mathrm{~mL})$ contained $20 \mathrm{mM}$ uridine and $10 \mathrm{mM}$ 2-amino-6-chloropurine. (a) The reaction was conducted in a thermostatic oscillator at a $\mathrm{pH}$ of $8.0\left(20 \mathrm{mM} \mathrm{Na}_{2} \mathrm{HPO}_{4} / \mathrm{KH}_{2} \mathrm{PO}_{4}\right)$ with temperature ranging from $30{ }^{\circ} \mathrm{C}$ to $65{ }^{\circ} \mathrm{C}$ for $36 \mathrm{~h}$. (b) The reaction was carried out at a temperature of $55^{\circ} \mathrm{C}$ for $60 \mathrm{~h}$ in $20 \mathrm{mM} \mathrm{Na} 2 \mathrm{HPO}_{4} / \mathrm{KH}_{2} \mathrm{PO}_{4}$ buffer systems with $\mathrm{pH}$ ranging from 5.0 to 8.0.

\subsection{Effect of BbPyNP and AmPNP Ratio on the Biosynthesis of 2-Amino-6-chloropurine Ribonucleoside (2)}

In the previous literature, Zhou et al. used GtPNP $(0.2 \mathrm{mg} / \mathrm{mL})$ and TtPyNP $(0.1 \mathrm{mg} / \mathrm{mL})$ to synthesize purine nucleoside analogs with a higher yield [16]. Subsequently, their lab also reported that purine nucleosides with higher yields were also synthesized by the combination of TtPyNP $(0.05 \mathrm{mg} / \mathrm{mL})$ and GtPNP $(0.05 \mathrm{mg} / \mathrm{mL})$ [21]. Purine nucleosides were both synthesized with a high yield under different enzyme ratios. In this context, the optimization of the enzymes ratio is also necessary to reduce the cost of production in the industry. It was found that a low ratio of BbPyNP: AmPNP (2:20 $\mu \mathrm{g} / \mathrm{mL})$ also resulted in the higher yield (95.1\%) of the 2-amino-6-chloropurine 
ribonucleoside (2) product (Figure 5). The phosphorolysis of uridine as a ribose donor produces the $\alpha$-D-ribose-1-phosphate and free uracil in a phosphate buffer with BbPyNP. $\alpha$-D-ribose-1-phosphate is an unstable compound [25], and the excessive compound will decompose. In the higher ratio of $B b P y N P$ for $A m P N P$, transglycosylation cannot catch up with decomposition of ribose- 1 alpha-phosphate. A low ratio of $B b P y N P$ : $A m P N P(2: 20 \mu \mathrm{g} / \mathrm{mL})$ would reduce the usage of the PyNP by 25 times than previous reported in [21], which could give a reduction in cost and show the important value of producing it in the industry.

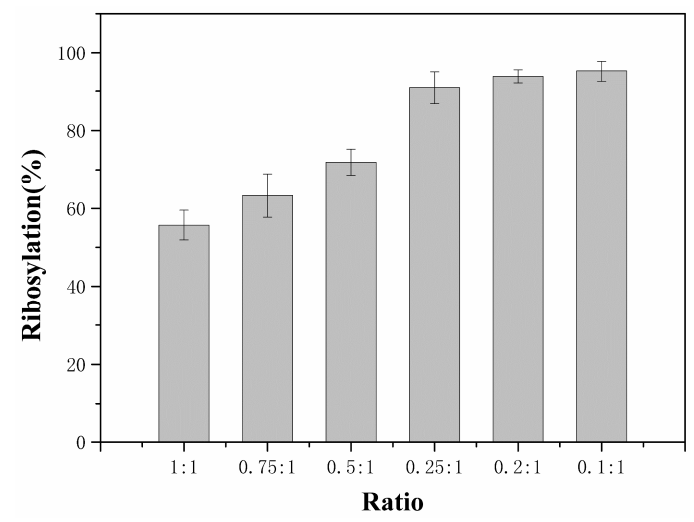

Figure 5. Effect of the ratio of B $b y \mathrm{PNP}: A m \mathrm{PNP}$ on biosynthesis of 2-amino-6-chloropurine ribonucleoside. Process for synthesis of 2-amino-6-chloropurine ribonucleoside was shown in Scheme 2. Using $20 \mathrm{mM}$ uridine and 10mM 2-amino-6-chloropurine, the reaction mixture $(1.0 \mathrm{~mL})$ contained purified B $b$ PyNP (85 IU/mg for uridine) and purified AmPNP (83 IU/mg) at different ratios (the concentration of $A m \mathrm{PNP}$ was set at $20 \mu \mathrm{g} / \mathrm{mL})$. The reaction was carried out at $\mathrm{pH} 7.0(20 \mathrm{mM}$ $\mathrm{Na}_{2} \mathrm{HPO}_{4} / \mathrm{KH}_{2} \mathrm{PO}_{4}$ ) and a temperature of $55^{\circ} \mathrm{C}$ for $36 \mathrm{~h}$, followed by analysis.

\subsection{Enzymatic Synthesis of Various Purine Nucleoside Analogs}

Various purine nucleoside analogs could be biosynthesized by coupling AmPNP and BbPyNP under optimum conditions for the one-pot, two-enzyme cascade reaction at yields ranging from $3.4 \%$ to 98.3\% (Table 2). 2-amino-6-chloropurine nucleoside was selected for confirmation and identified by the NMR spectrum (Supplementary Material Figures S21 and S22). NMR spectroscopic characterization of the product 2-amino-6-chloropurine ribonucleoside (2) was identical to the corresponding product when compared with the report [26].

In the previous literature, various purine nucleoside analogs were also synthesized by NPs (Table 3). For 2,6-diaminopurine ribonucleoside (1), the PNP from A. pernix K1 was reported to synthesize the product (1) at an approximate yield of $60 \%$ [27]. The PNP from T. thermophilus (TtPNP) and the PyNP from the G. thermoglucosidasius (GtPyNP) [16] synthesized product (1) with the highest yield of $95.3 \%$ at a lower substrate concentration of $2 \mathrm{mM}$ uridine and $1 \mathrm{mM}$ 2,6-diaminopurine. For 2-amino-6-chloropurine ribonucleoside (2), using PNP from A. hydrophila, product (2) was synthesized at a yield of $93 \%$ in the presence of $0.42 \mathrm{mM} 7$-methylguanosine iodide and $0.14 \mathrm{mM}$ 2-amino-6-chloropurine [26]. In comparison, using uridine as donor, the conversion of product (1) synthesized by the combination of $A m P N P$ and $B b P y N P$ reached higher than $98.3 \%(9.8 \mathrm{mM})$ at higher concentrations of $20 \mathrm{mM}$ uridine and $10 \mathrm{mM}$ 2,6-diaminopurine. Other products of ribo-purine nucleoside analogs were obtained at a yield of $95.1 \%$ for product (2) and $92.3 \%$ for product (3), corresponding to a nucleoside production level of $9.5 \mathrm{mM}$ and $9.2 \mathrm{mM}$, respectively. Although the concentrations of substrates were higher than the reports, the conversions of both product (1) and product (2) synthesized by the combination of $A m \mathrm{PNP}$ and $B b \mathrm{PyNP}$ still reached more than 95\%. Also, some halogenated purine $2^{\prime}$-deoxyribonucleosides were synthesized by the combination of $A m P N P$ and BbPyNP. Specifically, 2-Chloro-2'-deoxyadenosine (Cladribine) was formed at a yield of $60.4 \%$, and an antiviral drug ribavirin was also formed with a yield of $73.7 \%$ with the transglycosylation reaction. 
These results indicate that $A m \mathrm{PNP}$ is an excellent biocatalyst for the industrial production of purine nucleoside analogs.

Table 3. Biosynthesis of purine nucleoside analogs.

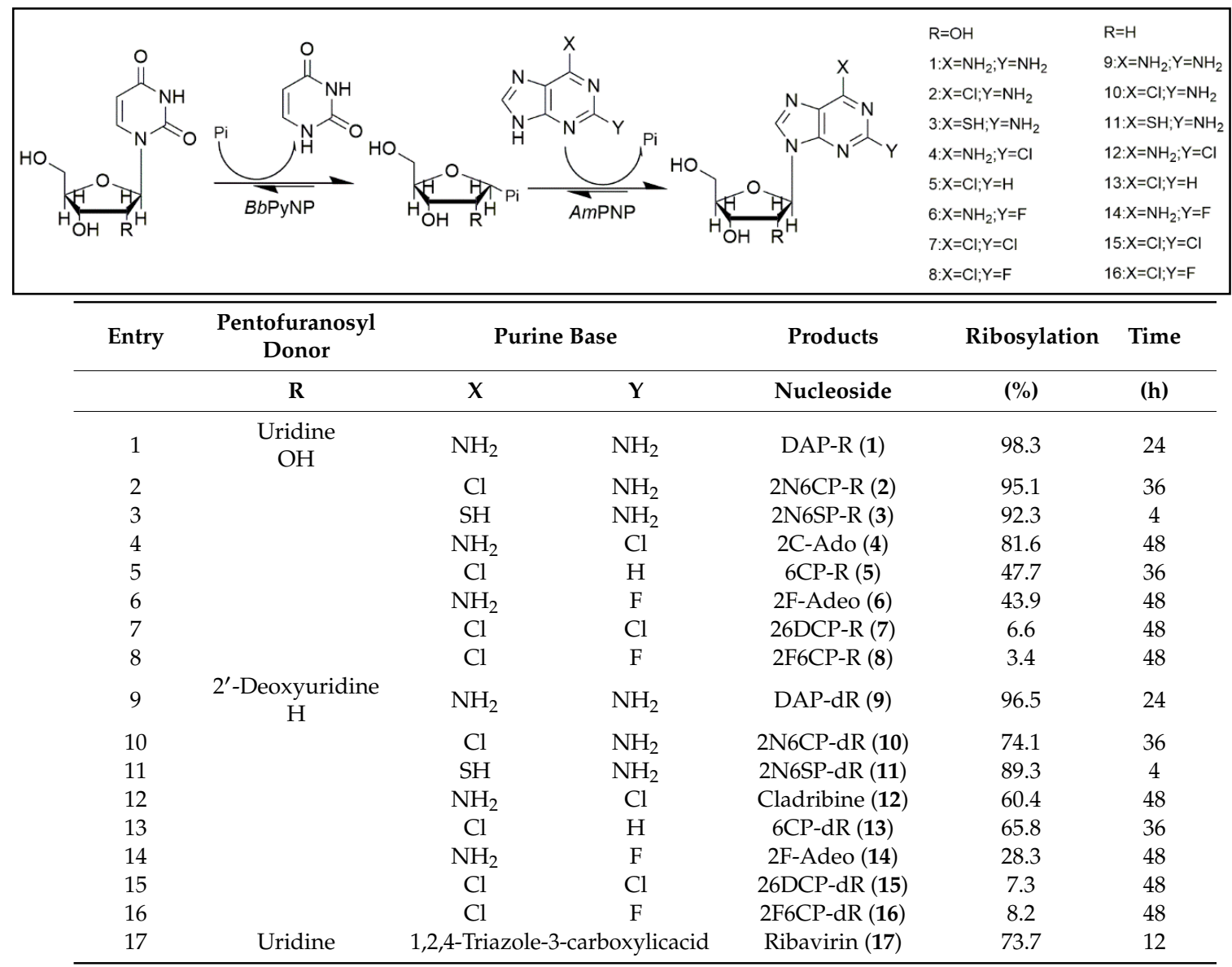

Temperature: $55^{\circ} \mathrm{C}$. Enzymes: BbPyNP: AmPNP. 2:20 $\mu \mathrm{g} / \mathrm{mL}$; Medium: $20 \mathrm{mM} \mathrm{Na}{ }_{2} \mathrm{HPO}_{4} / \mathrm{KH}_{2} \mathrm{PO}_{4}$ buffer (pH 7.0); Substrates: pentofuranosyl donor: Purine base. 20:10 mM (entries 1-3, 5, 7-11, 13, 15-17); 10: $5 \mathrm{mM}$ (entries 4, 6, $12,14)$.

\section{Materials and Methods}

\subsection{Materials}

Nucleosides and purine bases were purchased from Aladdin (Shanghai, China). Other chemicals obtained were of analytical grade. Solvents used for high-performance liquid chromatography (HPLC) were of HPLC grade. The One Step Cloning Kit was purchased from Novoprotein (Shanghai, China). The vector pET-28a (+) and strain E. coli BL21(DE3) were obtained from Novagen (New haven, CT, USA) for plasmid amplification or protein expression. The restriction enzymes and T4 DNA ligase were purchased from Takara (Kyoto, Japan).

\subsection{Cloning, Expression, and Purification of AmPNP from A. migulanus AM007}

The mesophilic strain A. migulanus AM007 was previously isolated and deposited at the China Center for Type Culture Collection (CCTCC, Wuhan, China) with the accession number CCTCC NO. M2016404. The gene encoding PNP from A. migulanus AM007 was amplified, and then cloned into pET-28a (+) using the Nhe I and BamH I restriction enzymes. The primers used were as following: forward, 5'-CGCGGCAGCCATATGGCTAGCATTGCAGCGCATATTTCTG $-3^{\prime}$ with the Nhe I restriction site (underlined), and reverse, 5'-ACGGAGCTCGAATTCGGATCC 
TTATAATTTTTGAATAACAGCTTTT-3' with the BamH I restriction site (underlined). The recombinant plasmids were constructed using the ClonExpress II One Step Cloning Kit, and then they were transformed into E. coli BL21(DE3) (Novagen). Cell growth was carried out at $37^{\circ} \mathrm{C}$. When the optical density at $600 \mathrm{~nm}$ (OD600) of the cell suspension reached 0.6, and after which the temperature was lowered to $20^{\circ} \mathrm{C}$, isopropyl $\beta$-D-1-thiogalactopyranoside (IPTG) was added with a final concentration of $1 \mathrm{mM}$ for the enzyme expression. The cells were harvested by centrifugation $\left(12,000 \mathrm{rpm}, 4{ }^{\circ} \mathrm{C}\right.$, $10 \mathrm{~min}$ ) after induction for $8 \mathrm{~h}$. The cell pellets were resuspended in phosphate-buffered saline (PBS; $\mathrm{Na}_{2} \mathrm{HPO}_{4} / \mathrm{KH}_{2} \mathrm{PO}_{4}, 50 \mathrm{mM}, \mathrm{pH}$ 8.0) and subjected to ultrasonic fragmentation on ice using an GA92-IID ultrasonicator (Wuxi Shangjia Biotechnology Co., Ltd., Jiangsu, China). The solution of the recombinant protein with an N-terminal $6^{*}$ His-tag was obtained by centrifugation with the same conditions above, and then was purified with $\mathrm{Ni}^{2+}$-affinity chromatography. AmPNP was analyzed by sodium dodecyl sulfate polyacrylamide gel electrophoresis (SDS-PAGE) and its molecular mass was determined using gel-filtration chromatography on a Superdex 200 Increase 10/300 GL column (GE Healthcare, Buckinghamshire, UK). Protein concentrations were determined with bicinchoninic acid (BCA) Protein Assay Kit (Zhongke rRuitai, Biological Technology Co., Ltd., Beijing, China).

\subsection{Analysis of Enzyme Activity and Substrate Specificity}

One international unit of enzyme activity (IU) was defined as the amount of enzyme required to convert $1.0 \mu \mathrm{mol}$ of inosine per minute at $50{ }^{\circ} \mathrm{C}$ and a pH of 8.0 in $10 \mathrm{mM} \mathrm{Na}_{2} \mathrm{HPO}_{4} / \mathrm{KH}_{2} \mathrm{PO}_{4}$ with $10 \mathrm{mM}$ inosine as substrate. The reaction was performed by adding $50 \mu \mathrm{L}$ of enzyme $(15 \mu \mathrm{g} / \mathrm{mL})$ to $1.0 \mathrm{~mL}$ of the reaction mixture. Regular samples (every $5 \mathrm{~min}$ ) were taken, and $50 \mu \mathrm{L}$ of the reaction mixture was immediately added to $950 \mu \mathrm{L}$ methanol to stop the reaction. In the pretreatment method, samples were centrifuged for $5 \mathrm{~min}$ at 12,000 rpm to remove the precipitates, and further filtered through a $0.22 \mu \mathrm{m}$ pore size membrane. The prepared sample was analyzed by HPLC to quantitatively determine the reaction products. The conversion rates were calculated from the integration of the corresponding HPLC peaks.

Substrate specificity of the $A m P N P$ for the phosphorolysis reactions of various purine nucleosides were analyzed and quantified. The phosphorolysis reactions catalyzed by the enzyme toward different purine nucleosides $(10 \mathrm{mM})$ were conducted under $50^{\circ} \mathrm{C}$ and $\mathrm{pH} 8.0\left(10 \mathrm{mM} \mathrm{Na} 2 \mathrm{HPO}_{4} / \mathrm{KH}_{2} \mathrm{PO}_{4}\right)$ from $0 \mathrm{~h}$ to $48 \mathrm{~h}$. The activity assay was carried out as described in the analysis of enzyme activity, and the highest activity was set to $100 \%$.

\subsection{Effect of $p H$ on the Activity and Stability of AmPNP}

To measure the optimum $\mathrm{pH}$ for the phosphorolysis of inosine $(10 \mathrm{mM})$, the activity of the purified $A m \mathrm{PNP}$ was determined at $50{ }^{\circ} \mathrm{C}$ in $10 \mathrm{mM} \mathrm{Na} \mathrm{HPO}_{4} / \mathrm{KH}_{2} \mathrm{PO}_{4}$ buffer with a $\mathrm{pH}$ ranging from 5.0 to 8.0. To determine the stability of $A m \mathrm{PNP}$ under different $\mathrm{pH}$ conditions, the purified enzyme was incubated at $50{ }^{\circ} \mathrm{C}$ for $2 \mathrm{~h}$. Activity assay was carried out as described in Section 3.3, and the highest activity was set to $100 \%$. Controls without enzymes were performed in parallel.

\subsection{Effect of Temperature on the Activity and Thermostability of AmPNP}

The activity-temperature profile of $A m \mathrm{PNP}$ was determined from $30^{\circ} \mathrm{C}$ to $80{ }^{\circ} \mathrm{C}(\mathrm{pH} 8.0$, $\left.\mathrm{Na}_{2} \mathrm{HPO}_{4} / \mathrm{KH}_{2} \mathrm{PO}_{4}\right)$ in the presence of the inosine $(10 \mathrm{mM})$ substrate. The thermostability of $A m \mathrm{PNP}$ was determined by measuring the residual activity at temperatures ranging from $30^{\circ} \mathrm{C}$ to $70{ }^{\circ} \mathrm{C}$ from 1 to $12 \mathrm{~h}$. The activity assay was carried out as described in Section 3.3, and the highest activity was set to $100 \%$. Controls without enzymes were performed in parallel.

\subsection{Effect of Temperature and $p H$ on Two-Enzyme Biosynthesis of 2-Amino-6-chloropurine Ribonucleoside (2)}

The reaction mixture $(1.0 \mathrm{~mL})$ contained $20 \mathrm{mM}$ uridine and $10 \mathrm{mM}$ 2-amino-6-chloropurine, purified $B b \mathrm{PyNP}$, and purified $A m \mathrm{PNP}$. To investigate the effect of temperature on the transglycosylation, the reaction was conducted in a thermostatic oscillator at a $\mathrm{pH}$ of $8.0\left(20 \mathrm{mM} \mathrm{Na} 2 \mathrm{HPO}_{4} / \mathrm{KH}_{2} \mathrm{PO}_{4}\right)$ with 
temperatures ranging from $30^{\circ} \mathrm{C}$ to $65^{\circ} \mathrm{C}$ for $36 \mathrm{~h}$. To determine the optimum $\mathrm{pH}$, the reaction was carried out at a temperature of $55^{\circ} \mathrm{C}$ for $36 \mathrm{~h}$ in $20 \mathrm{mM} \mathrm{Na}_{2} \mathrm{HPO}_{4} / \mathrm{KH}_{2} \mathrm{PO}_{4}$ buffer systems with the $\mathrm{pH}$ ranging from 5.0 to 8.0. The products were detected with HPLC in triplicates.

\subsection{Effect of BbPyNP and AmPNP Ratio on the Biosynthesis of 2-Amino-6-chloropurine Ribonucleoside (2)}

Using $20 \mathrm{mM}$ uridine as the donor, the reaction mixture $(1.0 \mathrm{~mL})$ contained purified BbPyNP ( $85 \mathrm{IU} / \mathrm{mg}$ for uridine) and purified $A m \mathrm{PNP}(83 \mathrm{IU} / \mathrm{mg}$ ) at different ratios (the concentration of $A m \mathrm{PNP}$ was set at $20 \mu \mathrm{g} / \mathrm{mL}$, and $B b P y N P$ and $A m P N P$ were set with various ratios of 1:1, 0.75: 1, 0.5:1, 0.25: 1, $0.2: 1$, and $0.1: 1$, respectively). The reaction was carried out at $\mathrm{pH} 7.0$ and a temperature of $55^{\circ} \mathrm{C}$ for $36 \mathrm{~h}$, followed by analysis.

\subsection{Enzymatic Synthesis of Various Purine Nucleoside Analogs}

Using uridine or 2'-deoxyuridine as donor, the one-pot, two-enzyme reaction was carried out with $B b P y N P$ and $A m P N P(2: 20 \mu \mathrm{g} / \mathrm{mL})$ in $20 \mathrm{mM} \mathrm{Na} 2 \mathrm{HPO}_{4} / \mathrm{KH}_{2} \mathrm{PO}_{4}$ buffer $(\mathrm{pH} 7.0)$ and at $55^{\circ} \mathrm{C}$. Different purine bases were used to test the following: $10 \mathrm{mM}$ 2-chloroadenine (2CA), $10 \mathrm{mM}$ 2,6-diaminopurine (DAP), $10 \mathrm{mM}$ 6-thioguanine (2N6SP), $10 \mathrm{mM}$ 6-chloro-2-fluoropurine (6C2FP), $10 \mathrm{mM}$ 2,6-dichloropurine (26DCP), $5 \mathrm{mM}$ 2-fluoroadenine (2FA), $10 \mathrm{mM}$ 2-amino-6-chloropurine $(2 \mathrm{~N} 6 \mathrm{CP})$, and $5 \mathrm{mM} 6$-chloropurine $(6 \mathrm{CP})$. The reaction mixture was obtained and then analyzed by HPLC to quantitatively determine the reaction products. The pretreatment method was carried out as described in Section 3.3.

\subsection{HPLC Analysis and Purification and Structural Determination of the Product}

The reaction mixtures were analyzed by HPLC coupled with a detector at $254 \mathrm{~nm}$ (but $280 \mathrm{~nm}$ for nucleosides 7 and 15, and $207 \mathrm{~nm}$ for nucleoside 17) and the C18 column $(250 \times 4.6 \mathrm{~mm}, 5 \mu \mathrm{m})$ at $30^{\circ} \mathrm{C}$. The flow rate was set at $1.0 \mathrm{~mL} / \mathrm{min}$, and the injection volume was $5 \mu \mathrm{L}$. Gradient elution was done from 0 to $8 \mathrm{~min}$ using 95/5 (v/v, here and subsequently) water/methanol, from 8 to 9 min with water/methanol changed from $95 / 5$ to 80/20, from 9 to 20 min with a water/methanol ratio of 80/20, from 20 to $22 \mathrm{~min}$ with a water/methanol ratio of $80 / 20$, and from 22 to $25 \mathrm{~min}$ with a water/methanol ratio of $95 / 5$ to analyze the enzymatic synthesis of purine nucleosides. Elution was performed from 0 to $20 \mathrm{~min}$ using only water for the analysis of nucleoside 17. HPLC retention times and HPLC chromatograms of the transglycosylations are given in the Supplementary Materials (Figures S2-S20). The percentage conversion was calculated on the basis of the depletion of the sugar acceptor compound (heterocyclic base) and monitoring the formation of the nucleoside products, with the conversion (\%) calculated as [product area/(product area + base area) $] \times 100 \%$. The product was separated and purified with flash column chromatography using ethyl acetate/methanol $(95 / 5, v / v)$. The structure determination of the products was found by mass spectrometry using a Voyager-DE MALDI-TOFMS apparatus (Applied Biosystems, Franklin Lakes, NJ, USA) and by nuclear magnetic resonance (NMR) using a model (Bruker AV-400 spectrometer (Bruker, Basel, Switzerland).

\section{Conclusions}

In summary, we cloned and characterized a new trimeric PNP from A. migulanus AM007, which showed good thermostability and a broad range of $\mathrm{pH}$ stability. Then, a one-pot, two-enzyme mode of transglycosylation reactions was successfully constructed by combining BbPyNP and AmPNP for the production of purine nucleoside analogs. Mainly, the ratio of $B b P y N P$ and $A m P N P$ was optimized in the one-pot, two-enzyme reactions, which greatly reduced the production cost. Highly efficient synthesis of the purine nucleoside analogs was successfully achieved in the one-pot, two-enzyme transglycosylation reactions catalyzed by $A m \mathrm{PNP}$ and $B b \mathrm{PyNP}$ for the higher concentrations of substrates (pentofuranosyl donor: purine base; 20:10 mM) with a low enzyme ratio of BbPyNP: AmPNP $(2: 20 \mu \mathrm{g} / \mathrm{mL})$. Therefore, the newly trimeric $A m P N P$ is a promising biocatalyst for the industrial production of purine nucleoside analogs. 
Supplementary Materials: The following are available online, Figure S1: Effect of proportion of glycosyl donor and purine base on the biosynthesis of 2-amino-6-chloropurine ribonucleoside, Figures S2-S20: HPLC dates of synthesis of various purine nucleoside analogs, Figure S21: 1H-NMR spectrum of 2-amino-6-chloropurine nucleoside, Figure S22: 13C-NMR spectrum of 2-amino-6-chloropurine nucleoside, Table S1: Identities of the reported PNPs, Table S2: Half-life of AmPNP at different temperature.

Author Contributions: G.L., J.C. and B.H. designed the experiments, G.L., T.C. and S.L. conducted the experiments, G.L. and J.C. analyzed the date, G.L., J.C. and B.H. wrote the main manuscript. All authors reviewed the manuscript. All authors have read and agreed to the published version of the manuscript.

Funding: This work was supported by the National Key Research and Development Program of China (2018YFA0902000), National Natural Science Foundation of China (81673321, 21506099), Natural Science Foundation of Jiangsu province (Grant No. BK20181379). We also thank the Jiangsu Synergetic Innovation Center for Advanced Bio-Manufacture (No. XTC1812) and Postgraduate Research \& Practice Innovation Program of Jiangsu Province (KYCX18_1107).

Acknowledgments: The authors thank Wu bin for helpful discussions.

Conflicts of Interest: The authors declare no conflict of interest.

\section{References}

1. Seley-Radtke, K.L.; Yates, M.K. The evolution of nucleoside analogue antivirals: A review for chemists and non-chemists. Part 1: Early structural modifications to the nucleoside scaffold. Antivir. Res. 2018, 154, 66-86. [CrossRef] [PubMed]

2. Galmarini, C.M.; Mackey, J.R.; Dumontet, C. Nucleoside analogues and nucleobases in cancer treatment. Lancet Oncol. 2002, 3, 415-424. [CrossRef]

3. Tănase, C.I.; Drăghici, C.; Hanganu, A.; Pintilie, L.; Maganu, M.; Volobueva, A.; Sinegubova, E.; Zarubaev, V.V.; Neyts, J.; Jochmans, D.; et al. New HSV-1 Anti-Viral 1'-Homocarbocyclic Nucleoside Analogs with an Optically Active Substituted Bicyclo[2.2. 1]Heptane Fragment as a Glycoside Moiety. Molecules 2019, 24, 2446.

4. Robak, T.; Robak, P. Purine nucleoside analogs in the treatment of rarer chronic lymphoid leukemias. Curr. Pharm. Des. 2012, 18, 3373-3388. [CrossRef]

5. Bonate, P.L.; Arthaud, L.; Cantrell, W.R., Jr. Discovery and development of clofarabine: A nucleoside analogue for treating cancer. Nat. Rev. Drug Discov. 2006, 5, 855-863. [CrossRef]

6. Gerster, J.F.; Jones, J.W.; Robins, R.K. Purine Nucleosides. IV. The Synthesis of 6-Halogenated 9- $\beta$-D-Ribofuranosylpurines from Inosine and Guanosine1. J. Org. Chem. 1963, 28, 945-948. [CrossRef]

7. Liu, J.; Robins, M.J. $\mathrm{S}_{\mathrm{N}}$ Ar Displacements with 6-(Fluoro, Chloro, Bromo, Iodo, and Alkylsulfonyl) purine Nucleosides: Synthesis, Kinetics, and Mechanism1. J. Am. Chem. Soc. 2007, 129, 5692-5968. [CrossRef]

8. Xia, R.; Xie, M.S.; Niu, H.Y. Efficient synthesis of nebularine and vidarabine via dehydrazination of (hetero) aromatics catalyzed by $\mathrm{CuSO}_{4}$ in water. Green Chem. 2014, 16, 1077-1081. [CrossRef]

9. Xu, S.; Yao, P.; Chen, G.; Wang, H. A new synthesis of 2-chloro-2'-deoxyadenosine (Cladribine), CdA. Nucleosides Nucleotides Nucleic Acids 2011, 30, 353-359. [CrossRef]

10. Schulmeier, B.E.; Cantrell, W.R., Jr.; Bauta, W.E. Preparation of a fludarabine intermediate via selective alkylation of 2-fluoroadenine. Nucleosides Nucleotides Nucleic Acids 2006, 25, 735-745. [CrossRef]

11. Serra, I.; Daly, S.; Alcantara, A.R.; Bianchi, D.; Terreni, M.; Ubiali, D. Redesigning the synthesis of vidarabine via a multienzymatic reaction catalyzed by immobilized nucleoside phosphorylases. RSC Adv. 2015, 5, 23569-23577. [CrossRef]

12. Hassan, A.E.A.; Shuto, S.; Matsuda, A. Nucleosides and nucleotides. 124 . Chemical reactivity of the sugar moiety of $2^{\prime}$-deoxy-2'-methylidene pyrimidine nucleosides: Synthesis of $3^{\prime}$-amino- $2^{\prime}$, 3 '-dideoxy-2'-methylidene pyrimidine nucleosides via [2, 3]-sigmatropic rearrangement of allylic selenides as potential antitumor agents. Tetrahedron 1994, 50, 689-700.

13. Rao, J.R.; Schinazi, R.F.; Chu, C.K. Enantioselective synthesis and antiviral activity of purine and pyrimidine cyclopentenyl C-nucleosides. Bioorg. Med. Chem. 2007, 15, 839-846. [CrossRef] [PubMed]

14. Bzowska, A.; Kulikowska, E.; Shugar, D. Purine nucleoside phosphorylases: Properties, functions, and clinical aspects. Pharmacol. Ther. 2000, 88, 349-425. [CrossRef]

15. Pugmire, M.J.; Ealick, S.E. Structural analyses reveal two distinct families of nucleoside phosphorylases. Biochem. Soc. 2001, 361, 1-25. 
16. Zhou, X.; Szeker, K.; Jiao, L.Y.; Oestreich, M.; Mikhailopulo, I.A.; Neubauer, P. Synthesis of 2, 6-dihalogenated purine nucleosides by thermostable nucleoside phosphorylases. Adv. Synth. Catal. 2015, 357, 1237-1244. [CrossRef]

17. De Azevedo, W.F., Jr.; Canduri, F.; dos Santos, D.M.; Silva, R.G.; de Oliveira, J.S.; de Carvalho, L.P.S.; Santos, D.S. Crystal structure of human purine nucleoside phosphorylase at $2.3 \AA$ resolution. Biochem. Biophy. Res. Comm. 2003, 308, 545-552. [CrossRef]

18. Lewis, A.S.; Glantz, M.D. Bovine brain purine-nucleoside phosphorylase purification, characterization, and catalytic mechanism. Biochemistry 1976, 15, 4451-4457. [CrossRef]

19. Jensen, K.F.; Nygaard, P. Purine nucleoside phosphorylase from Escherichia coli and Salmonella typhimurium: Purification and some properties. Eur. J. Biochem. 1975, 51, 253-265. [CrossRef]

20. Ubiali, D.; F Morelli, C.; Rabuffetti, M.; Cattaneo, G.; Serra, I.; Bavaro, T.; Speranza, G. Substrate specificity of a purine nucleoside phosphorylase from Aeromonas hydrophila toward 6-substituted purines and its use as a biocatalyst in the synthesis of the corresponding ribonucleosides. Curr. Org. Chem. 2015, 19, 2220-2225. [CrossRef]

21. Zhou, X.; Yan, W.; Zhang, C.; Yang, Z.; Neubauer, P.; Mikhailopulo, I.A.; Huang, Z. Biocatalytic synthesis of seleno-, thio-and chloro-nucleobase modified nucleosides by thermostable nucleoside phosphorylases. Cataly. Comm. 2019, 121, 32-37. [CrossRef]

22. Liu, K.; Zhou, Y.; Zhang, J.; Chu, J.; Zhang, Y.; He, B. A thermostable pyrimidine nucleoside phosphorylase from Brevibacillus borstelensis LK01 for synthesizing halogenated nucleosides. Biotechnol. Lett. 2017, 39, 1903-1910. [CrossRef] [PubMed]

23. Mei, Y.; He, B.; Liu, N.; Ouyang, P. Screening and distributing features of bacteria with hydantoinase and carbamoylase. Microbiol. Res. 2009, 164, 322-329. [CrossRef] [PubMed]

24. Zhu, S.; Song, D.; Gong, C.; Tang, P.; Li, X.; Wang, J.; Zheng, G. Biosynthesis of nucleoside analogues via thermostable nucleoside phosphorylase. Appl. Microbiol. Biot. 2013, 97, 6769-6778. [CrossRef] [PubMed]

25. Quintiliani, M.; Balzarini, J.; McGuigan, C. Design, synthesis, and biological evaluation of C1-phosphonamidate analogues of 2-deoxy-d-ribose-1-phosphate. Tetrahedron 2013, 69, 9111-9119. [CrossRef]

26. Ubiali, D.; Serra, C.D.; Serra, I.; Morelli, C.F.; Terreni, M.; Albertini, A.M.; Speranza, G. Production, characterization and synthetic application of a purine nucleoside phosphorylase from Aeromonas hydrophila. Adv. Synth. Catal. 2012, 354, 96-104. [CrossRef]

27. Zhu, S.; Ren, L.; Wang, J.; Zheng, G.; Tang, P. Two-step efficient synthesis of 5-methyluridine via two thermostable nucleoside phosphorylases from Aeropyrum pernix. Bioorg. Med. Chem. Lett. 2012, 22, 2102-2104. [CrossRef]

Sample Availability: Not available.

(C) 2019 by the authors. Licensee MDPI, Basel, Switzerland. This article is an open access article distributed under the terms and conditions of the Creative Commons Attribution (CC BY) license (http://creativecommons.org/licenses/by/4.0/). 